\title{
Ontogeny of the Drosophila larval hematopoietic organ, hemocyte homeostasis and the dedicated cellular immune response to parasitism
}

\author{
JOANNA KRZEMIEN\#, MICHELE CROZATIER and ALAIN VINCENT* \\ Université de Toulouse 3, Centre de Biologie du Développement, UMR 5547 CNRS/UPS, Toulouse, France
}

\begin{abstract}
Over the years, the fruit fly Drosophila melanogaster has become a major invertebrate model to study developmental and evolutionary aspects of both humoral and cellular aspects of innate immunity. Drosophila hematopoiesis which supplies three types of circulating hemocytes, occurs in two spatially and temporally distinct phases during development. The first embryonic phase is described in detail in accompanying reviews in this Int. J. Dev. Biol. Special Issue. The second phase takes place at the end of larval development in a specialised hematopoietic organ, termed the lymph gland. We review here recent studies on the ontogeny of the lymph gland, focusing on the formation and role of the Posterior Signalling Center which acts as a niche for hematopoietic progenitors. We then report recent progress in understanding the dedicated cellular immune response of Drosophila larvae against parasitization by Hymenopterae, a common threat for many Dipterae. This response involves the differentiation of lamellocytes, a cryptic cell fate, revealing the high degree of plasticity of Drosophila hematopoiesis. We end up by integrating studies in Drosophila within a more general picture of insect hematopoiesis and hemocyte homeostasis.
\end{abstract}

KEY WORDS: Drosophila, hematopoiesis, lymph gland, immunity, niche, signalling

Introduction to the Drosophila cellular immune system, the hemocytes

Drosophila is a holometabolous insect which spends most of its life cycle in decaying organic matter such as rotting fruit, an environment enriched in microorganisms that constantly challenges the immune system. Innate responses can be schematically divided into humoral and cellular components mediated by secreted factors like antimicrobial peptides (AMP) and specific cells, the hemocytes, respectively (Lemaitre and Hoffmann, 2007). Drosophilahematopoiesis which provides circulating hemocytes, occurs in two spatially and temporally distinct phases (Crozatier and Meister, 2007; Evans et al., 2003; Holz et al., 2003). The first, embryonic phase is described in detail in an accompanying review (Waltzer et al., 2010). The second phase takes place during larval development in a specialised hematopoietic organ, termed the lymph gland (LG). The LG starts to form at the end of embryogenesis and growths during larval stages (see below) before dispersal at metamorphosis and the releasing of hemocytes in the hemolymph (Crozatier et al., 2007; Crozatier and Meister, 2007). Three different types of hemocytes can be found in Drosophila. The first and most abundant type is the plasmatocytes that are functionnally compared to vertebrate macrophages. They are responsible for the removal of apoptotic cells and microorganisms during the entire life fly cycle (Wood and Jacinto, 2007). Plasmocytes are highly motile cells, owing to well developed actin rich filopodia and lamellopodia which allow them to explore their environment (Tepass et al., 1994; Wood et al., 2006; Zanet et al., 2009). In the embryo, plasmatocytes migrate to and scavenge damage tissue using chemotactic cues (Stramer et al., 2005). In the larva, plasmatocytes are recruited to tissue wound to participate in damaged healing through direct, adhesive capture from

\footnotetext{
Abbreviations used in this paper: AMP, antimicrobial peptide; LG, lymph gland; PSC, posterior signalling center.
}

\footnotetext{
*Address correspondence to: Alain Vincent or Michele Crozatier. Université de Toulouse 3, UPS, Centre de Biologie du Développement, Bâtiment 4R3, 118 route de Narbonne, F-31062 Toulouse, France. Tel: +33-61-5582-89/90; http://www-cbd.ups-tlse.fr/ - e-mail: vincent@cict.fr or crozat@cict.fr

\#Present address: Department of Zoology, University of Cambridge, Downing Street, Cambridge CB2 3EJ, UK.
}

Final author corrected PDF published online: 16 July 2010.

ISSN: Online 1696-3547, Print 0214-6282

(1) 2010 UBC Press

Printed in Spain 
circulation, similar to blood cells in vertebrates (Babcock et al., 2008). This behavior is consistent with the hypothesis that the ability to recognise and adhere to damaged or "non self" tissue is an ancestral feature of immune cells. According to the "dangerhypothesis", the immune system would be alerted by endogeneous stress signals released from injured tissues (Matzinger, 2002; Seong and Matzinger, 2004; Pastor-Pareja et al., 2008). Recent studies have also brought to light possible links between the phagocytic activity of hemocytes and activation of the systemic humoral response. Mutants for psidin, which encodes a protein associated with lysosomes expressed in hemocytes, fail to lyse phagocytosed bacteriae and do not synthesize the antimicrobial peptide defensin upon bacterial infection (Berman et al., 2004). A similar phenotype was reported for mutants of eater, a gene encoding a phagocytosis receptor expressed by hemocytes (Kocks et al., 2005; Kurucz et al., 2007; Somogyi et al., 2008). Recent genetic ablation of. plasmatocytes has revealed the essential contribution of phagocytes, both to embryonic development, including morphogenesis of the central nervous system and the resistance of Drosophila adults upon systemic infection with specific bacteriae. It confirmed that phagocytosis is a critical effector mechanism of the cellular immune response (Charroux and Royet, 2009; Defaye etal., 2009). Interestingly, plasmatocytemediated phagocytosis could also participate in a specific and durable, induced protection against specific pathogens, a kind of immune memory. Flies primed with a sublethal dose of Streptococcus pneumoniae are protected against a lethal dose of the same bacteria when challenged one week later and this specific memory depends on phagocytosis by plasmatocytes (Pham et al., 2007). Evidence for a memory effect has also been obtained in the social insect bumblebee Bombus terrestris (Sadd and Schmid-Hempel, 2006). The molecular basis of this "immune memory" of insects, a property thought so far to be specific to vertebrates could possibly involve recognition of bacteria by specific membrane proteins expressed by hemocytes such as the immunoglobulin-domain Down-syndrome-cell-adhesion (Dscam) molecules (Dong et al., 2006). Finally, it was very recently shown that Drosophila plasmatocytes use macro-autophagy to fight against invading intracellular bacteriae, such as Listeria monocytogenes, through intracellular recognition of a bacterial peptidoglycan by a pattern recognition receptor, (PGRP-LE) that is expressed by hemocytes. Autophagy which prevents intracellular growth of L. Monocytogenes and promotes host survival following this infection was confirmed in ex vivocultured hemocytes (Yano and Kurata, 2008). Together, the recent reports on new plasmatocyte functions open the way to compare analyses of the signalling pathways involved in immune memory and autophagy as an immune response between insects and mammals.

The second type of Drosophilahemocytes, the crystal cells are also generated during both embryonic and larval hematopoiesis but their role in embryos remains unknown (Wood and Jacinto, 2007). They make about $5 \%$ of circulating hemocytes in the larval hemolymph and are not found in adult flies (Lanot et al., 2001). Crystal cells owe their name to big crystals of zymogen proPhenoloxydase (proPO1 and ProPO2), a component of the melanisation enzymatic cascade that are stored in their cytoplasm (Ashida, 2004). Crystal cell-release of components of the melanisation cascade plays a key role in formation of the clot which immobilises bacteria, prevents their spreading and pro- motes their killing since melanin and its biosynthetic by-products are directly toxic to micro-organisms. Clotting is critical in limiting hemolymph loss and creating a physical immune barrier following would healing in insects. The phenoloxydase originating from crystal cells acts during clot maturation to produce a hard clot by cross-linking components of the primary soft clot (Jiravanichpaisal et al., 2006). Melanisation could also be mediated by Pro-PO3 a third proPO isoform active in its zymogen form and expressed by lamellocytes, the third type of hemocytes (Nam et al., 2008).

The Drosophila lamellocytes are flat, large, adhesive cells which, unlike plasmatocytes and crystal cells, are produced by larval hematopoiesis (Lanot et al., 2001). They form a multilayered, overlapping sheath of cells around foreign objects too large to be phagocytised, a process called encapsulation. Lamellocytes are rarely observed in healthy larvae but differentiate in very large number in response to specific challenges such as wasp parasitism. In nature, at least around 50 hymenoptera species parasite Drosophila larvae (Carton and David, 1985) among which Leptopilina boulardi, a species widely used in laboratories to study the Drosophilaimmune response. L. boulardi adult females lay eggs into the hemocel of young Drosophila larvae and use the host body as a nutrition source for the developing offspring. The detection of parasitoid eggs, probably by circulating plasmatocytes (Russo et al., 1996), triggers lamellocyte differentiation in the LG and release in the hemolymph. Encapsulation of the egg is followed by its melanisation and death, probably through the effect of cytotoxic free radicals or quinons generated by the melanin synthesis process (Vass and Nappi, 2000). The killed egg stays as a melanotic capsule in the larva and adult as an inert body. If the fly immune response fails, a wasp hatches from the pupa at the expense of the fly. Parasitoid wasps use different infection strategies to avoid the host response (Schlenke et al., 2007). For example, Asobara tabidacan passively evade the immune response because its eggs attach to the host tissue thanks to their sticky chorion and get embedded in host tissue inaccessible to hemocytes. L. boulardieggs typically attach to host tissues which provide a partial passive protection (Prevost et al., 2005; Rizki et al., 1990). Another way to escape is an active suppression based on specific components introduced into the larval host by the female wasp at the time of oviposition. For example, L. heterotomawasps inject virus like particles (VLP) produced by the so-called long glands. The proteins present in the $L$. heterotoma VLP inhibit the encapsulation by changing the morphology of the lamellocytes, resulting in their diminished adhesive ability and, eventually, apoptosis whereas the venom of L. Boulardi virulent strains appears to block the induction and release of lamellocytes from the LG (see references in Schlenke et al., 2007).

\section{Ontogeny of the larval hematopoietic organ, the lymph gland}

The embryonic primordium of the LG is part of the cardiogenic mesoderm which gives also rise to the dorsal vessel, the Drosophilaheart made of two cell types, the contractile cardiomyoblasts and the associated non-myogenic pericardial cells (Rugendorf et al., 1994) reviewed in (Cripps and Olson, 2002; Zaffran and Frasch, 2002). Homo and hetero-topic cell transplantation experiments mapped the blastoderm LG anlage between 50 and 55\% 
Egg Length in the thoracic lateral mesoderm, correlating with patterns of expression of some enhancer trap lines (Rugendorf et al., 1994). The fate of the transplanted cells further showed that the LG originated from only a few progenitors which are not specified before the second post-blastoderm mitosis (Holz et al., 2003). More recently, the pattern of expression of the COE transcription factor Collier/Knot (Col) suggested that the LG originates from discrete clusters of few cells in the dorsal mesoderm of thoracic segments and confirmed that LG progenitors are already specified at the time of germ-band elongation (stage 11), at least partly independent of srp (serpent) which encodes a GATA factor required for embryonic hematopoiesis ((Crozatier et al., 2004); Fig. 1A). The clusters of Col-expressing cells subsequently coalesce to form the primary LG lobes. At the same time, Col expression gets restricted to the 2-3 posterior-most cells of the LG, in segment T3 (Fig. 1A). This late expression of Col prefigures the so-called Posterior Signalling Center (PSC), first identified in LG of 3rd instar larvae ((Lebestky et al., 2003), see below). Although Col expression in stage 11 embryos suggested that the LG originates from two thoracic cell clusters, expression of another transcription factor (TF), the $\mathrm{C} 2 \mathrm{H} 2$ zinc-finger protein Odd (Odd-skipped), at stage 13 suggests that the LG could be contributed by cells originating from each of the 3 thoracic segments. Unlike Col, however, Odd is also expressed from stage 13 in precursor cells of pericardial cells in abdominal segments and thus constitutes a marker of both lymph gland and pericardial cells, termed also nephrocytes (Mandal et al., 2007; Ward and Coulter, 2000). A detailed appraisal of the transcriptional control of cardiogenic mesoderm formation and LG specification is outside the scope of this review. In brief, the GATA factor Pannier (Pnr) and the Homeobox Tinman (Tin) are required for both development of the dorsal vessel and lymph gland while Srp, another GATA factor is specifically required for specification of the lymph gland, in addition to specification of embryonic hemocytes from the anterior mesoderm (Fig. 1A, (Mandal et al., 2004), and review by (Waltzer et al., 2010)). tailup (tup) which encodes a LIM homeodomain transcription factor expressed in all cardioblasts, pericardial cells and LG cells is also required for normal heart and LG formation (Mann et al., 2009; Tao et al., 2007) as well as hand, a direct target of Tin, Tup and GATA factors which encodes a conserved bHLH transcription activator (Han and Olson, 2005; Han et al., 2006; Lo et al., 2007). Antennapedia (Antp) is the only homeotic gene expressed in the thoracic cardiac mesoderm. Antp expression is restricted to cardiac cells in the posterior T3 and anterior A1 segments and LG cells in posterior T3, those cells that keep expressing Col and prefigure the PSC (Mandal et al., 2004; Perrin et al., 2004). Homothorax (Hth) is expressed in a complementary pattern to Antp in the LG, such that at the end of embryogenesis, two populations of cells, Hth and Col/Antp positive, respectively, can be distinguished ((Mandal et al., 2007), Fig. 1B). Antp is required to maintain the PSC-specific co/transcription from stage 15 (Mandal et al., 2007). This observation was somewhat unexpected since, in absence of homeotic gene function (Scr-, Antp-, Ubx-, abdA-, AbdB-embryos) or Ubx, $a b d A$ - double mutants the whole cardiac tube develops as anterior aorta with Odd-expressing cells along the entire length of the tube also expressing Col. Conversely, ectopic expression of either Antp, Ubx, or AbdA in the entire mesoderm results in the loss of Col-expressing cells (Mandal et al., 2004; Perrin et al., 2004). Together, these homeotic gain-of-function and loss-offunction data suggested that pericardial cells and lymph gland progenitor cells are closely related fates, with pericardial cells adopting a "LG identity" in absence of homeotic gene function. Antp could possibly exert a secondary role in specifying PSC cells. This interpretation is supported by Odd and Srp staining of tup mutant embryos. While most of the LG and pericardial cells are lost in these embryos, the number of Col-positive cells detected at stage 15 is comparable to wild type, indicating that the posterior part of the LG forms in absence of tup and srp function (Tao et al., 2007). Together, these observations indicate that the specification of PSC cells is controlled by a specific regulatory network. Clonal analyses have suggested that at least a subset of LG cells could originate from bipotential cardioblast-lymph gland progenitors (Mandal et al., 2004). A complete view of the lineage relations between the different cell types in the lymph gland, and Drosophila heart is, however, still lacking. In summary, LG speci-

A Stage 11

B

\section{Stage 16}

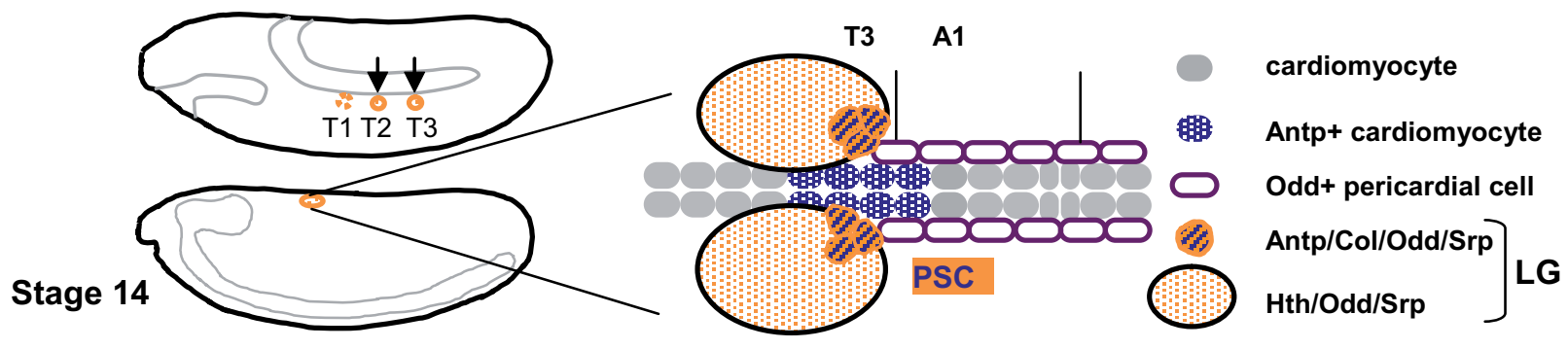

lateral view

dorsal view

Fig. 1. Ontogeny of the lymph gland in the Drosophila embryo. (A) Diagrammatic representation of Col expression (orange) in the lymph gland anlage. Col expression is observed in two separate clusters of cells (black arrows) in the dorsal-most mesoderm of thoracic segments T2 and T3 at the germ band extension stage (stage 11 embryos). Odd expression identifies a third cluster in segment T1 (broken circle). The clusters of Col + Odd expressing cells coalesce to form the primary lobe of the $L G$ at stage 14. Col then becomes progressively restricted to the posterior-most cells of the $L G$ as shown by the partial overlap with Odd expression. (B) Schematic drawing of the LG, cardiac and pericardial cells at embryonic stage 16. The expression domains of Antp, Col, Odd and Srp are colour-coded (see text for references). 
fication within the embryonic cardiac mesoderm is controlled by a complex hierarchical network of transcription factors (Fig. 1 and review by (Waltzer et al., 2010)). One key event, more specifically emphasized here, is the restriction of co/transcription to cells issued from the LG primordium which express Antp and will give rise to the PSC.

During larval development, the embryonic, primary LG lobes grow in size while secondary, posterior lobes form (Johnson etal., 2007). When fully developed in third instar larvae, primary lobes contain each about 3000 cells (compared to 30 at the end of the embryogenesis) and represent the main Drosophila larval hematopoietic site (Lanot et al., 2001). Before the LG disperses and releases hemocytes into circulation in response to a peak of ecdysone at metamorphosis (Sorrentino et al., 2002), all plasmatocytes and crystal cells, either circulating or sessile, originate from embryonic hematopoiesis. A mixture of embryonic and lymph gland hemocytes is thus found in pupae and the adult fly (Holz et al., 2003). Until now, no hematopoietic site has been described in the adult fruit fly (Holz et al., 2003). However, it might be important to consider that, when the LG disperses, it contains a mixture of differentiated and non differentiated hemocytes, including those present in the variable numbers of posterior lobes whose function has not been thoroughly investigated. Lymph gland cells give rise to both circulating and sessile hemocytes which stay attached to the integument after metamorphosis (Holz et al., 2003). Whether some of them are immature progenitors remains a possibility to be explored.

\section{The control of larval hematopoiesis: the key role of the Posterior Signalling Center}

Perhaps related to very different time scales, only few parallels have been established between embryonic and larval Drosophila hematopoiesis. The transcription factor, Lozenge (Lz) plays a key role in crystal cell specification, in both embryos and larvae (Lebestky etal., 2000). Similarly, U-shaped which acts in repressing the crystal cell fate in embryos by binding to a specific isoform of Srp is also involved in repressing the lamellocyte fate in the LG (Ferjoux et al., 2007; Sorrentino et al., 2007) and accompanying review by (Waltzer et al., 2010). Gcm and Gcm2 which are strictly required to endow embryonic hemocytes with a plasmatocyte fate are not expressed in the lymph gland ((Bataille et al., 2005) review by (Waltzer et al., 2010). At the opposite, Odd is only expressed during larval hematopoiesis (Ward and Coulter, 2000). A more conflicting issue is Notch signalling which has been shown to be essential for crystal cell differentiation in larvae(Duvic et al., 2002; Lebestky et al., 2000) while its role during embryonic hematopoiesis remains controversial (Bataille et al., 2005).

A key step in the description of larval hematopoiesis was the detailed examination of a fully developed $3^{\text {rd }}$ instar LG by optical microscopy. It allowed to distinguish two zones, in addition to the PSC: a cortical zone (CZ) with a granular appearance surrounding a smooth and compact medullary zone (MZ) (Jung et al., 2005). The CZ contains differentiated plasmatocytes and crystal cells while the $M Z$ contains undifferentiated pro-hemocytes (Fig. 2). Powerful cell tracing experiments further showed that $C Z$ cells originate from the $M Z$. The mode and control of the $M Z>C Z$ transition are currently the subject of intense investigation (see below). Apart from the lack of expression of differentiation mark- ers, the $M Z$ can be visualised by the expression of several genes and reporter expression driven by domeless-gal4, a transgene inserted in the domeless (dome) upstream region ((Bourbon etal., 2002; Jung et al., 2005); Table 1). dome encodes the Drosophila receptor of the evolutionarily conserved JAK/STAT ( nase/Signal Transducer and Activators of Transcription) pathway (review by (Agaisse and Perrimon, 2004)). The JAK/STAT signalling pathway was discovered from studying the role of interferon in the control of immune responses in vertebrates. (for review (Heinrich etal., 2003; Kristensen etal., 2005). Initial evidence that JAK/STAT signalling could be involved in Drosophila cellular immunity came from analysis of dominant-gain of function mutations of the JAK kinase hopscotch (hop), such as the thermosensitive mutation hop ${ }^{\text {Tum-l }}$. When kept at restrictive tem-

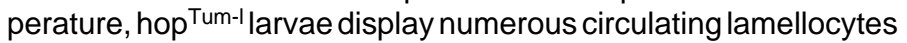
and melanotic pseudotumors in absence of wasp infestation

TABLE 1

\section{GENES EXPRESSED IN THE ANTERIOR LOBE OF THE LYMPH GLAND, EITHER IN THE ENTIRE LOBE, THE POSTERIOR SIGNALLING CENTER, THE MEDULLARY ZONE OR THE CORTICAL ZONE}

\begin{tabular}{|c|c|c|}
\hline Markers & Expression in the LG & References \\
\hline Serpent (Srp) & whole & Letbestky et al. 2000 \\
\hline Hemese $(\mathrm{He})$ & whole & Kurucz et al. 2003 \\
\hline PDGF- and VEGF-receptor related (Pvr) & whole & Jung et al. 2005 \\
\hline Odd-skipped (Odd) & whole & Jung et al. 2005 \\
\hline Viking (Vkg-GFP) & whole & Jung et al. 2005 \\
\hline U-shaped (Ush) & whole & $\begin{array}{l}\text { Sorrentino 2007; } \\
\text { Gao } 2009\end{array}$ \\
\hline dSPARC & whole & Irving et al. 2005 \\
\hline $\operatorname{cg} 9372$ & whole & Irving et al. 2005 \\
\hline imaginal disc growth factor (idfg1) & whole & Irving et al. 2005 \\
\hline Serrate (Ser) & PSC+scattered cells in LG & Lebestky et al. 2003 \\
\hline Collier (Col) & PSC & Crozatier et al. 2004 \\
\hline Antennapedia (Antp) & PSC & Mandal et al. 2007 \\
\hline Hedgehog $(\mathrm{Hh})$ & PSC & Mandal et al. 2007 \\
\hline DE-cadherin (DE-cad) & $M Z$ & Jung et al. 2005 \\
\hline domeless (dome) (P-gal4) & $M Z$ & Jung et al. 2005 \\
\hline thioester-containing protein (tep4) & $M Z$ & Irving et al. 2005 \\
\hline Patched (Ptc) & $\mathrm{MZ}$ & Mandal et al. 2007 \\
\hline Cubitus interruptus $(\mathrm{Ci})$ & $M Z$ & Mandal et al. 2007 \\
\hline Latran (Lat) & $\mathrm{MZ}$ & Makki et al., 2010 \\
\hline Cut (Ct) & $\mathrm{CZ}$ & Jung et al. 2005 \\
\hline Nimrod1 (NimC1) & CZ (plasmatocytes) & Kurucz et al. 2007 \\
\hline Crocquemort (Crq) & CZ (plasmatocytes) & Irving et al. 2005 \\
\hline Peroxidasine (Pxn) & CZ (plasmatocytes) & $\begin{array}{l}\text { Jung et al. 2005; } \\
\text { Irving et al. } 2005\end{array}$ \\
\hline Lozenge (Lz) & CZ (crystal cells) & Lebestky et al. 2000 \\
\hline Prophenoloxidase (proPO) & CZ (crystal cells) & Duvic et al. 2002 \\
\hline diphenol oxidase $A 3$ (doxA3) & CZ (crystal cells) & Crozatier et al. 2004 \\
\hline PS4 integrin $\alpha$ chain ( $\alpha \mathrm{PS} 4$ ) & (lamellocytes) & Krzemien et al. 2007 \\
\hline misshapen (msn) (P-lacZ) & (lamellocytes) & Braun et al. 1997 \\
\hline L1 & (lamellocytes) & Kurucz et al. 2003 \\
\hline puckered (puc) (P-lacZ) & (lamellocytes) & Irving et al. 2005 \\
\hline Filamin-240/Cherio (Cher) & (lamellocytes) & Rus et al. 2006 \\
\hline Wingless & MZ, PSC, CC precursors & Sinenko et al., 2009 \\
\hline Frizzled 2 (DFz2) & MZ, PSC & Sinenko et al., 2009 \\
\hline
\end{tabular}

Expression in specific hemocytes is indicated in brackets.

Gene names in italic letters indicate that the expression is detected by in situ hybridisation, whereas $\mathrm{P}$-element enhancer trap insertions are indicated by $\mathrm{P}$-gal4 or P-lacZ. Abbreviations: LG, lymph gland; Whole, entire lobe; PSC, posterior signalling center; $M Z$, medullary zone; CZ, cortical zone. 
(Hanratty and Dearolf, 1993; Harrison et al., 1995; Luo et al., 1995; O'Shea et al., 2002; Sorrentino et al., 2007). Conversely, loss of hop function leads to a complete absence of lamellocyte differentiation upon wasp infestation (Sorrentino et al., 2004). This led to the conclusion that up-regulation of JAK/STAT signalling was instrumental in triggering lamellocyte differentiation. The situation is certainly more complex, however, since JAK/STAT signalling has recently been shown to play an opposite role in hemocyte homeostasis, that is, preserving the pro-hemocyte character of MZ cells (Krzemien et al., 2007). Maintenance of JAK/STAT signalling in the MZ depends upon activity of the PSC. The PSC was initially described as a small cluster of posterior LG cells expressing the Notch $(\mathrm{N})$ ligand Serrate (Ser) in third instar larvae. Based in part on the roles of $\mathrm{N}$ signalling in crystal cell formation and Ser as the Drosophila $\mathrm{N}$ ligand in this process (Duvic etal., 2002; Lebestky etal., 2003), it was proposed that the posterior cluster of Ser positive LG cells could act as a signalling centre instructing neighbouring cells to become crystal cells (Lebestky et al., 2003). This conclusion was contradicted, however, by the observation that crystal cells differentiate in col ${ }^{1}$ mutant LG ( $\mathrm{col}^{1}$ is a null allele) which lacks the PSC, suggesting that Ser expression in scattered cells in the LG, and not the PSC, was required for crystal cell differentiation (Crozatier et al., 2004). Nevertheless, the notion of a posterior signalling centre was fundamental, since the PSC turned out to control other essential aspects of larval hematopoiesis. The first observation was that PSC-depleted larvae are unable to mount a cellular immune response in response to parasitoid wasp egg-laying (Crozatier et al., 2004). The authors also noticed an increased differentiation of hemocytes that occurs in LG lacking a PSC in absence of wasp infestation, suggesting other roles of the PSC in normal physiological conditions. Two independent reports have now shown that the PSC acts as a specific micro-environment, for hematopoietic progenitors (Fig. 2). In the first report, Krzemien et al., (2007) reinvestigated the col mutant phenotype using $\mathrm{MZ}$ and $\mathrm{CZ}$ specific markers and showed that, in absence of PSC, there is a global, premature differentiation of all hematopoietic progenitors.
This premature differentiation is linked to the loss of JAK/STAT signalling activity in $M Z$ cells, indicating that remote control of JAK/STAT activity by the PSC is a key to the control of hemocyte homeostasis in the Drosophila LG. Upon wasp infestation, JAK/ STAT signalling is switched off in the entire $M Z$, allowing massive differentiation of lamellocytes at the expense of the pool of prohemocytes (Makki et al., 2010). Since in absence of PSC, no lamellocytes differentiate after wasp infestation, it indicated that the maintenance of a pool of multipotent progenitors in the $M Z$ is a prerequisite for Drosophila larvae to be able to mount a dedicated cellular response against parasites (Crozatier et al., 2004; Krzemien et al., 2007). The Friend of GATA protein U-shaped has now to been shown to act downstream of JAK/STAT signalling to preserve pro-hemocyte potency (Gao et al., 2009). In the second report, (Mandal et al., 2007) used Antp mutants which lack Col expression in the PSC to assess the role of the PSC in 3rd instar larvae. They first showed that PSC cells specifically express Hedgehog $(\mathrm{Hh})$ downstream of Antp, while $M Z$ cells express downstream components of the Hh pathway, the receptor $P$ atched (Ptc) and transcription factor Cubitus interruptus (Ci) (Table 1). As observed with co/l mutants, a massive differentiation of hemocytes was observed in $h h^{t s}$ mutants or when expression of a dominantnegative form of $\mathrm{Ci}$, the transcriptional effector of the pathway was targeted to the MZ. It was therefore proposed that Hh produced by PSC cells could act at distance in the lymph gland, as it was described in other Drosophila tissues (Chuang and Kornberg, 2000; Mandal et al., 2007) to maintain a pool of prohemocytes. Brought together, the observations of Krzemien and Mandal and co-authors suggest that PSC cells could non cell-autonomously control the level of JAK/STAT signalling in the MZ, via the secretion of $\mathrm{Hh}$ (Fig. 2). Other possible hypotheses should be considered, however, such as the existence of relay cells which would transform short-range signalling from the PSC into longrange signalling in the entire $\mathrm{MZ}$, similar to the activation of Dpp expression in cells close to the Hh source in the wing disk (review by Lawrence and Struhl, 1996). Very recent evidence from UASGal4 targeted loss and gain of function of components of the
A

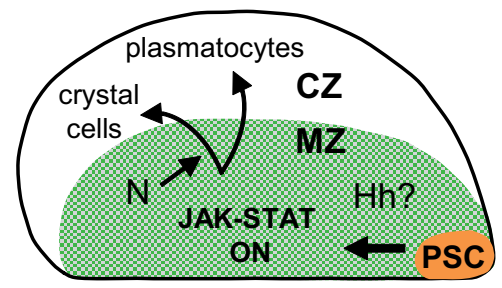

B

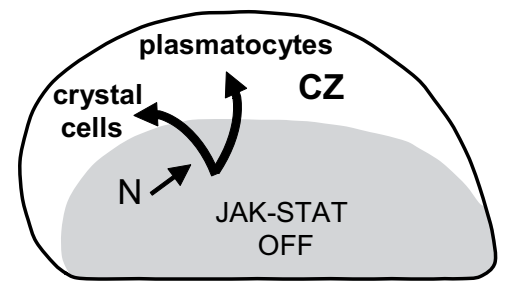
col mutant
C

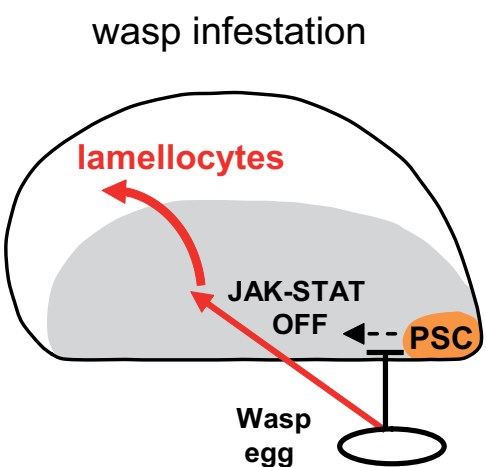

Fig. 2. A model for larval hematopoiesis in the Drosophila lymph gland in normal conditions and upon wasp parasitization. (A) Schematic drawing of a LG primary lobe in wt mid-3rd instar larvae, showing the PSC (orange), the medullary zone (MZ) which contains pro-hemocytes (shaded green) and the cortical zone (CZ) which contains differentiating hemocytes (white). During normal development, the PSC acts non-cell autonomously, possibly via Hh signalling, to maintain JAK/STAT signalling in the MZ, thereby maintaining a pool of pro-hemocytes. (B) In col mutant larvae that lack a PSC, there is loss of the MZ and premature differentiation of hemocytes. (C) Wasp parasitization antagonises the signalling from the PSC to the $M Z$, leading to down regulation of JAK/STAT signalling. Pro-hemocytes are instructed to differentiate into lamellocytes but the nature of the instructive signal remains unknown. (Krzemien et al., 2007). 
Wingless $(\mathrm{Wg})$ signalling pathway suggest a dual role of $\mathrm{Wg}$ signalling during larval hematopoieisis: maintenance of prohemocytes and maintenance of the PSC (Sinenko et al., 2009). In this context, it is worth emphasizing that PSC cells extend numerous long filopodia, raising the possibility that they could communicate with a specific subset of $M Z$ cells via direct cell-cell contacts (Krzemien et al., 2007). Finally, Owusu-Hansa and Banerjee (Owusu-Ansah and Banerjee, 2009) observed that the pro-hemocyte population in the LG shows significantly increased ROS levels in the last larval stage but not at earlier developmental stages. By monitoring the timing of hemocyte differentiation upon either further increased or reduced level of ROS in the MZ, these authors could conclude that high ROS level in progenitors are an intrinsic factor sensitising these progenitors to differentiation. High ROS levels activate JNK signalling in hematopoietic progenitors, resulting in FoxO activation and down regulation of Polycomb activity which combinatorially can induce the differentiation of all three type of Drosophila hemocytes. Signalling via ROS needs now to be connected to other signalling pathways that operate in the hematopoietic progenitors, such as JAK/STAT signalling, in order to get an integrated view of the control of hematopoiesis in different environmental conditions (Vincent and Crozatier, 2010).

The key role of the PSC in maintenance of hematopoietic progenitors and regulation of their differentiation is very reminiscent of the vertebrate hematopoietic stem cell (HSC) niche, a term coined 30 years ago to describe the structural and regulatory micro-environment sustaining long-term renewal of HSC located in the bone marrow. Although the concept of stem cell niche has long been proposed, the cellular and molecular basis for HSC niche activity has remained a complicated issue (see Kiel and Morrison, 2008). One difficulty in drawing detailed parallels between the PSC and vertebrate HSC is that a functional test for an HSC character, that is the ability to give rise to all hematopoietic lineages and restore long-term hematopoiesis in lethally irradiated recipients (Domen and Weissman, 1999; Matsuzaki et al., 2004), is not available in Drosophila. Other types of Drosophila niches have been well characterized, especially the ovarian and testicular niches which control Germ-line Stem Cell (GSC) maintenance. Communication from the niche to GSCs and reciprocal involves multiple signalling pathways, including the TGF $\beta$, JAK/ STAT, Hh and Wnt pathways in the ovary and TGF $\beta$ and JAK/ STAT in the testis, pointing to the complexity and versatility of stem cells/niche interactions in Drosophila. (Fuller and Spradling, 2007). In parallel to GSCs, other types of, tissue-specific, Drosophila stem cells have recently been characterized, including neural and intestinal stem cells, bringing to light a diversity of cellular and molecular mechanisms involved in stem cell maintenance (Kohlmaier and Edgar, 2008).

$\mathrm{col}$ plays a key role in the PSC but does not seem to be expressed in other known Drosophila niches. Col is a member of the family of COE transcription factors which includes mammalian EBF (Éarly B cell Factor) (Daburon et al., 2008; Dubois and Vincent, 2001). ebf(1) was shown to be essential for B-lymphocyte specification and differentiation (Lin and Grosschedl, 1995; Pongubala et al., 2008) but possible links between coland ebf functions in the immune system have remained scant. Mouse ebf2expression in immature osteoblasts which constitute a major component of the HSC niche in the vertebrate bone marrow
(Kieslinger et al., 2005; Wilson and Trumpp, 2006) raises, however, the intriguing possibility of functional parallels between the roles of Col and EBF2 in Drosophila and vertebrate hematopoiesis, respectively. It further suggests an ancestral role of COE proteins in controlling cellular aspects of metazoan innate immunity.

\section{Hemocyte types and numbers in different insects; plasticty in the cellular immune responses}

Drosophila melanogaster has become a major invertebrate model to study developmental and evolutionary aspects of innate immunity, owing to the power of genetic manipulations. But how does the knowledge acquired on fruit flies compare with what has been learnt from studies performed in other insects? Insect hemocytes have traditionally been classified according to morphological, histochemical and functional criteria and only more recently on additional, molecular criteria. Description of hemocytes in diverse insect orders including Lepidoterae, Dipterae, Orthopterae, Blattariae, Coleopterae, Hymenopterae, Hemipterae and Collembola considered four types of hemocytes: granular cells, plasmatocytes, spherule cells and oenocytoids (Lavine and Strand, 2002; Ribeiro and Brehelin, 2006. Only the spherule cells have not been described in $D$. melanogaster. Drosophila plasmatocytes can be assimilated to granular hemocytes, the professional phagocytes and crystal cells to oenocytoids, the cells that carry phenoloxidase pro-enzymes and play a prominent role in melanization. The lamellocytes are a more complex issue. Ultra-structural and functional characteristics suggest that $D$. melanogaster lamellocytes are equivalent to circulating "plasmatocytes" of other insect orders, described as the cells involved in encapsulation of foreign bodies too large to be engulfed by phagocytosis. However, it is necessary to recall that lamellocyte fate is a cryptic fate in $D$. melanogaster. Another case of cryptic hemocyte fate has been described in the tobacco hornwporm Manducta sexta, that is only revealed following infection (Dean, 2004) and shares morphological properties with Drosophilalamellocytes, suggesting that they may be functionally equivalent cells. It is also interesting to recall that the ability to differenciate lamellocytes in response to an immune challenge is not shared by all Drosophila species. Drosophila subobscura larvae, for example, are unable to differentiate lamellocytes and encapsulate parasitic eggs or other types of foreign bodies (Eslin and Doury, 2006). Parasitoid wasps are a common threat to many insects, but it appears that different parasites of the same host use different infection strategies, including immune-suppressive strategies (Schlenke et al., 2007). The molecular co-evolution of these strategies and the dedicated cellular immune responses displayed by different insect larvae is an entirely new field of investigation.

\section{Concluding remarks}

Over the years, our understanding of hematopoiesis in the fruit fly Drosophila melanogaster has made considerable progress. Many unsolved questions subsist, however, among which the question of whether hematopoietic cells with bona fide stem-cell character do exist in the Drosophila lymph gland and survive metamorphosis. Further characterisation of cell lineages in the 
lymph gland and the role of the PSC as a hematopoietic niche will certainly provide new insights into the cellular and molecular mechanisms by which niches control the balance between stem cell self-renewal and differentiation. The role of the filopodia extending from PSC cells and the extracellular matrix surrounding the LG and the PSC, in the control of LG growth, and hemocyte differentiation and dispersal at metamorphosis remain to be explored. Finally, studies of hematopoiesis in other insect models, in both normal and immune-challenged conditions will give a broader evolutionary perspective to studies so far mainly performed in Drosophila.

\section{Acknowledgements}

This work was supported by CNRS, a European Marie Curie PhD Training programme, Ministère de la Recherche (ACl Biologie Cellulaire, Moléculaire et Structurale and ANR programme Blanc) and Association pour la Recherche sur le Cancer. JK benefited from fellowships from Ministére des Affaires Etrangères (programme Eiffel) and ARC.

\section{References}

AGAISSE, $\mathrm{H}$. and PERRIMON, N. (2004). The roles of JAK/STAT signaling in Drosophila immune responses. Immunol Rev 198: 72-82.

ASHIDA, M. (2004). Activation of prophenoloxidase cascade with peptidoglycan. Tanpakushitsu Kakusan Koso 49: 1168-1173.

BABCOCK, D.T., BROCK, A.R., FISH, G.S., WANG, Y., PERRIN, L., KRASNOW, M.A. and GALKO, M.J. (2008). Circulating blood cells function as a surveillance system for damaged tissue in Drosophila larvae. Proc Natl Acad Sci USA 105: 10017-10022.

BATAILLE, L., AUGE, B., FERJOUX, G., HAENLIN, M. and WALTZER, L. (2005). Resolving embryonic blood cell fate choice in Drosophila: interplay of GCM and RUNX factors. Development 132: 4635-4644.

BERMAN, B.P., PFEIFFER, B.D., LAVERTY, T.R., SALZBERG, S.L., RUBIN, G.M., EISEN, M.B. and CELNIKER, S.E. (2004). Computational identification of developmental enhancers: conservation and function of transcription factor binding-site clusters in Drosophila melanogasterand Drosophila pseudoobscura. Genome Bio/5: R61.

BOURBON, H.M., GONZY-TREBOUL, G., PERONNET, F., ALIN, M.F., ARDOUREL, C., BENASSAYAG, C., CRIBBS, D., DEUTSCH, J., FERRER, P., HAENLIN, M. et al. (2002). A P-insertion screen identifying novel $X$-linked essential genes in Drosophila. Mech Dev 110: 71-83.

CARTON, Y. and DAVID, J.R. (1985). Relation between the genetic variability of digging behavior of Drosophilalarvae and their susceptibility to a parasitic wasp. Behav Genet 15: 143-154.

CHARROUX, B. and ROYET, J. (2009). Elimination of plasmatocytes by targeted apoptosis reveals their role in multiple aspects of the Drosophila immune response. Proc Natl Acad Sci USA 106: 9797-9802.

CHUANG, P.T. and KORNBERG, T.B. (2000). On the range of hedgehog signaling. Curr Opin Genet Dev 10: 515-522.

CRIPPS, R.M. and OLSON, E.N. (2002). Control of cardiac development by an evolutionarily conserved transcriptional network. Dev Bio/246: 14-28.

CROZATIER, M., KRZEMIEN, J. and VINCENT, A. (2007). The hematopoietic niche: a Drosophila model, at last. Cell Cycle 6: 1443-1444.

CROZATIER, M. and MEISTER, M. (2007). Drosophila haematopoiesis. Cell Microbio/9: 1117-1126.

CROZATIER, M., UBEDA, J.M., VINCENT, A. and MEISTER, M. (2004). Cellular immune response to parasitization in Drosophila requires the EBF orthologue collier. PLOS Bio/2: E196.

DABURON, V., MELLA, S., PLOUHINEC, J.L., MAZAN, S., CROZATIER, M. and VINCENT, A. (2008). The metazoan history of the COE transcription factors. Selection of a variant $\mathrm{HLH}$ motif by mandatory inclusion of a duplicated exon in vertebrates. BMC Evol Bio/8: 131

DEAN, P., RICHARDS, E.H., EDWARDS, J.P., REYNOLDS, S.E. and CHARNLEY, K. (2004). Microbial infection causes the appearance of hemocytes with extreme spreading ability in monolayers of the tobacco hornworm Manduca sexta. Dev Comp Immunol. 28: 689-700.

DEFAYE, A., EVANS, I., CROZATIER, M., WOOD, W., LEMAITRE, B. and LEULIER, F. (2009). Genetic ablation of Drosophila phagocytes reveals their contribution to both development and resistance to bacterial infection. Journal of Innate Immunity 1: 322-334.

DOMEN, J. and WEISSMAN, I.L. (1999). Self-renewal, differentiation or death: regulation and manipulation of hematopoietic stem cell fate. Mo/Med Today 5 : 201-208.

DONG, Y., TAYLOR, H.E. and DIMOPOULOS, G. (2006). AgDscam, a hypervariable immunoglobulin domain-containing receptor of the Anopheles gambiae innate immune system. PLOS Bio/4: e229.

DUBOIS, L. and VINCENT, A. (2001). The COE-Collier/Olf1/EBF-transcription factors: structural conservation and diversity of developmental functions. Mech Dev 108: 3-12

DUVIC, B., HOFFMANN, J.A., MEISTER, M. and ROYET, J. (2002). Notch signaling controls lineage specification during Drosophilalarval hematopoiesis. Curr Bio/ 12: 1923-1927.

ESLIN, P. and DOURY, G. (2006). The fly Drosophila subobscura: a natural case of innate immunity deficiency. Dev Comp Immuno/30: 977-983.

EVANS, C.J., HARTENSTEIN, V. and BANERJEE, U. (2003) Thicker than blood: conserved mechanisms in Drosophila and vertebrate hematopoiesis. Dev Cell. 5: 673-690.

FERJOUX, G., AUGE, B., BOYER, K., HAENLIN, M. and WALTZER, L. (2007). A GATA/RUNX cis-regulatory module couples Drosophilablood cell commitment and differentiation into crystal cells. Dev Bio/305: 726-734.

FULLER, M.T. and SPRADLING, A.C. (2007). Male and female Drosophilagermline stem cells: two versions of immortality. Science 316: 402-404.

GAO, H., WU, X. and FOSSETT, N. (2009). Upregulation of the Drosophila Friend of GATA gene U-shaped by JAK/STAT signaling maintains lymph gland prohemocyte potency. Mol Cel/ Bio/29: 6086-6096.

HAN, Z. and OLSON, E.N. (2005). Hand is a direct target of Tinman and GATA factors during Drosophilacardiogenesis and hematopoiesis. Development 132 3525-3536.

HAN, Z., YI, P., LI, X. and OLSON, E.N. (2006). Hand, an evolutionarily conserved bHLH transcription factor required for Drosophila cardiogenesis and hematopoiesis. Development 133: 1175-1182.

HANRATTY, W.P. and DEAROLF, C.R. (1993). The Drosophila Tumorous-lethal hematopoietic oncogene is a dominant mutation in the hopscotch locus. Mol Gen Genet 238: 33-37.

HARRISON, D.A., BINARI, R., NAHREINI, T.S., GILMAN, M. and PERRIMON, N. (1995). Activation of a Drosophila Janus kinase (JAK) causes hematopoietic neoplasia and developmental defects. EMBO J14: 2857-2865.

HEINRICH, P.C., BEHRMANN, I., HAAN, S., HERMANNS, H.M., MULLER-NEWEN, G. and SCHAPER, F. (2003). Principles of interleukin (IL)-6-type cytokine signalling and its regulation. Biochem J374: 1-20

HOLZ, A., BOSSINGER, B., STRASSER, T., JANNING, W. and KLAPPER, R (2003). The two origins of hemocytes in Drosophila. Development 130: 49554962.

JIRAVANICHPAISAL, P., LEE, B.L. and SODERHALL, K. (2006). Cell-mediated immunity in arthropods: hematopoiesis, coagulation, melanization and opsonization. Immunobiology211: 213-236.

JOHNSON, A.N., BURNETT, L.A., SELLIN, J., PAULULAT, A. and NEWFELD, S.J (2007). Defective decapentaplegic signaling results in heart overgrowth and reduced cardiac output in Drosophila. Genetics 176: 1609-1624.

JUNG, S.H., EVANS, C.J., UEMURA, C. and BANERJEE, U. (2005). The Drosophila lymph gland as a developmental model of hematopoiesis. Development 132: 2521-2533.

KIEL, M.J. and MORRISON, S.J. (2008). Uncertainty in the niches that maintain haematopoietic stem cells. Nat Rev Immuno/8: 290-301.

KIESLINGER, M., FOLBERTH, S., DOBREVA, G., DORN, T., CROCI, L., ERBEN, R., CONSALEZ, G.G. and GROSSCHEDL, R. (2005). EBF2 regulates osteoblast-dependent differentiation of osteoclasts. Dev Cel/9: 757-767.

KOCKS, C., CHO, J.H., NEHME, N., ULVILA, J., PEARSON, A.M., MEISTER, M., STROM, C., CONTO, S.L., HETRU, C., STUART, L.M. et al. (2005). Eater, a 
transmembrane protein mediating phagocytosis of bacterial pathogens in Drosophila. Cel/123: 335-346.

KOHLMAIER, A. and EDGAR, B.A. (2008). Proliferative control in Drosophila stem cells. Curr Opin Cell Bio/20: 699-706.

KRISTENSEN, D.M., KALISZ, M. and NIELSEN, J.H. (2005). Cytokine signalling in embryonic stem cells. Apmis 113: 756-772.

KRZEMIEN, J., DUBOIS, L., MAKKI,R., MEISTER, M., VINCENT, A. AND CROZATIER, M. (2007). Control of blood cell homeostasis in Drosophilalarvae by the posterior signalling centre. Nature 446 Issue: 325-328.

KURUCZ, E., MARKUS, R., ZSAMBOKI, J., FOLKL-MEDZIHRADSZKY, K., DARULA, Z., VILMOS, P., UDVARDY, A., KRAUSZ, I., LUKACSOVICH, T., GATEFF, E. et al. (2007). Nimrod, a putative phagocytosis receptor with EGF repeats in Drosophila plasmatocytes. Curr Bio/17: 649-654.

LANOT, R., ZACHARY, D., HOLDER, F. and MEISTER, M. (2001). Postembryonic hematopoiesis in Drosophila. Dev Bio/230: 243-257.

LAVINE, M.D. and STRAND, M.R. (2002). Insect hemocytes and their role in immunity. Insect Biochem Mol Bio/32: 1295-1309.

LAWRENCE, P.A. and STRUHL, G. (1996). Morphogens, compartments, and pattern: lessons from Drosophila? Cel/85: 951-961.

LEBESTKY, T., CHANG, T., HARTENSTEIN, V. and BANERJEE, U. (2000). Specification of Drosophila hematopoietic lineage by conserved transcription factors. Science 288: 146-149.

LEBESTKY, T., JUNG, S.H. and BANERJEE, U. (2003). A Serrate-expressing signaling center controls Drosophila hematopoiesis. Genes Dev 17: 348-353.

LEMAITRE, B. and HOFFMANN, J. (2007). The Host Defense of Drosophila melanogaster. Annu Rev Immunol. 25: 697-743.

LIN, H. and GROSSCHEDL, R. (1995). Failure of B-cell differentiation in mice lacking the transcription factor EBF. Nature 376: 263-267.

LO, P.C., ZAFFRAN, S., SENATORE, S. and FRASCH, M. (2007). The Drosophila Hand gene is required for remodeling of the developing adult heart and midgut during metamorphosis. Dev Bio/311: 287-296.

LUO, H., HANRATTY, W.P. and DEAROLF, C.R. (1995). An amino acid substitution in the Drosophila hopTum-I Jak kinase causes leukemia-like hematopoietic defects. EMBO J14: 1412-1420.

MAKKI, R., MEISTER, M., PENNETIER, D., UBEDA, JM., BRAUN, A., DABURON, D., KRZEMIEN, J., BOURBON, H.M., ZHOU, R., VINCENT, A. and CROZATIER, M. (2010). A short receptor down-regulates JAK/STAT signalling to control the Drosophila cellular immune response. PLOS Biology, doi:10.1371/ journal.pbio.1000441

MANDAL, L., BANERJEE, U. and HARTENSTEIN, V. (2004). Evidence for a fruit fly hemangioblast and similarities between lymph-gland hematopoiesis in fruit fly and mammal aorta-gonadal-mesonephros mesoderm. Nat Genet36: 10191023.

MANDAL, L., MARTINEZ-AGOSTO, J.A., EVANS, C.J.,HARTENSTEIN, V. AND BANERJEE, U. (2007). A haematopoietic niche defined by Antennapedia expression uses Hedgehog for the maintenance of blood cell precursors in Drosophila. Nature 446: 320-324.

MANN, T., BODMER, R. and PANDUR, P. (2009). The Drosophila homolog of vertebrate Islet 1 is a key component in early cardiogenesis. Development 136: 317-326.

MATSUZAKI, Y., KINJO, K., MULLIGAN, R.C. and OKANO, H. (2004). Unexpectedly efficient homing capacity of purified murine hematopoietic stem cells. Immunity 20: 87-93.

MATZINGER, P. (2002). The danger model: a renewed sense of self. Science296: 301-305.

NAM, H.J., JANG, I.H., ASANO, T. and LEE, W.J. (2008). Involvement of prophenoloxidase 3 in lamellocyte-mediated spontaneous melanization in Drosophila. Mol Cells 26: 606-610.

O'SHEA, J.J., GADINA, M. and SCHREIBER, R.D. (2002). Cytokine signaling in 2002: new surprises in the Jak/Stat pathway. Cel/109 Suppl: S121-S131.

OWUSU-ANSAH, E. and BANERJEE, U. (2009). Reactive oxygen species prime Drosophilahaematopoietic progenitors for differentiation. Nature 461:537-541.

PASTOR-PAREJA, J.C., WU, M. and XU, T. (2008). an innate immune response of blood cells to tumors and tissue damage in Drosophila. Disease Models and mechanisms 1: 153.
PERRIN, L., MONIER, B., PONZIELLI, R., ASTIER, M. and SEMERIVA, M. (2004). Drosophilacardiac tube organogenesis requires multiple phases of Hox activity. Dev Bio/272: 419-431.

PHAM, L.N., DIONNE, M.S., SHIRASU-HIZA, M. and SCHNEIDER, D.S. (2007). A specific primed immune response in Drosophila is dependent on phagocytes. PLOS Pathog 3: e26.

PONGUBALA, J.M., NORTHRUP, D.L., LANCKI, D.W., MEDINA, K.L., TREIBER, T., BERTOLINO, E., THOMAS, M., GROSSCHEDL, R., ALLMAN, D. and $\mathrm{SINGH}, \mathrm{H}$. (2008). Transcription factor EBF restricts alternative lineage options and promotes B cell fate commitment independently of Pax5. Nat Immuno/9: 203-215.

PREVOST, G., ESLIN, P., DOURY, G., MOREAU, S.J. and GUILLOT, S. (2005). Asobara, braconid parasitoids of Drosophilalarvae: unusual strategies to avoid encapsulation without VLPs. J Insect Physio/51: 171-179.

RIBEIRO, C. and BREHELIN, M. (2006). Insect haemocytes: what type of cell is that? J Insect Physio/52: 417-429.

RIZKI, T.M., RIZKI, R.M. and CARTON, Y. (1990). Leptopilina heterotoma and L. boulardi: strategies to avoid cellular defense responses of Drosophila melanogaster. Exp Parasito/70: 466-475.

RUGENDORF, A., YOUNOSSI-HARTENSTEIN, A. and HARTENSTEIN, V. (1994). Embryonic origin and differentiation of the Drosophila heart. Roux's Arch. Dev.Biol. 203: 266-208.

RUSSO, J., DUPAS, S., FREY, F., CARTON, Y. and BREHELIN, M. (1996). Insect immunity: early events in the encapsulation process of parasitoid (Leptopilina boulardi) eggs in resistant and susceptible strains of Drosophila. Parasitology 112 (Pt 1): 135-142.

SADD, B.M. and SCHMID-HEMPEL, P. (2006). Insect immunity shows specificity in protection upon secondary pathogen exposure. Curr Bio/ 16: 1206-1210.

SCHLENKE, T.A., MORALES, J., GOVIND, S. and CLARK, A.G. (2007). Contrasting infection strategies in generalist and specialist wasp parasitoids of Drosophila melanogaster. PLOS Pathog 3: 1486-1501.

SEONG, S.Y. and MATZINGER, P. (2004). Hydrophobicity: an ancient damageassociated molecular pattern that initiates innate immune responses. Nat Rev Immuno/4: 469-478.

SINENKO, S.A., MANDAL, L., MARTINEZ-AGOSTO, J.A. and BANERJEE, U. (2009). Dual role of wingless signaling in stem-like hematopoietic precursor maintenance in Drosophila. Dev Cel/16: 756-763.

SOMOGYI, K., SIPOS, B., PENZES, Z., KURUCZ, E., ZSAMBOKI, J., HULTMARK, D. and ANDO, I. (2008). Evolution of genes and repeats in the Nimrod superfamily. Mol Biol Evol25: 2337-2347.

SORRENTINO, R.P., CARTON, Y. and GOVIND, S. (2002). Cellular immune response to parasite infection in the Drosophilalymph gland is developmentally regulated. Dev Bio/243: 65-80.

SORRENTINO, R.P., MELK, J.P. and GOVIND, S. (2004). Genetic analysis of contributions of dorsal group and JAK-Stat92E pathway genes to larval hemocyte concentration and the egg encapsulation response in Drosophila. Genetics 166: 1343-1356.

SORRENTINO, R.P., TOKUSUMI, T. and SCHULZ, R.A. (2007). The Friend of GATA protein U-shaped functions as a hematopoietic tumor suppressor in Drosophila. Dev Bio/311: 311-323.

STRAMER, B., WOOD, W., GALKO, M.J., REDD, M.J., JACINTO, A., PARKHURST, S.M. and MARTIN, P. (2005). Live imaging of wound inflammation in Drosophila embryos reveals key roles for small GTPases during in vivocell migration. JCell Biol 168: 567-573.

TAO, Y., WANG, J., TOKUSUMI, T., GAJEWSKI, K. and SCHULZ, R.A. (2007). Requirement of the LIM homeodomain transcription factor tailup for normal heart and hematopoietic organ formation in Drosophila melanogaster. Mol Cell Bio/27: 3962-3969.

TEPASS, U., FESSLER, L.I., AZIZ, A. and HARTENSTEIN, V. (1994). Embryonic origin of hemocytes and their relationship to cell death in Drosophila. Development 120: 1829-1837.

VASS, E. and NAPPI, A.J. (2000). Developmental and immunological aspects of Drosophilaparasitoid relationships. J Parasito/86: 1259-1270.

VINCENT, A. and CROZATIER, M. (2010). Neither too much nor too little:Reactive oxygen species levels regulate Drosophila hematopoiesis. J.Mol.Cell Biol. 2: 74-75. 
WALTZER, L., GOBERT, V., OSMAN, D. and HAELIN, M. (2010). Transcription factors interplay during Drosophila haematopoiesis. Int. J. Dev. Biol. 54: 11071115. (doi: 10.1387/ijdb.030354lw).

WARD, E.J. and COULTER, D.E. (2000). odd-skipped is expressed in multiple tissues during Drosophila embryogenesis. Mech Dev 96: 233-236.

WILSON, A. and TRUMPP, A. (2006). Bone-marrow haematopoietic-stem-cell niches. Nat Rev Immuno/6: 93-106.

WOOD, W., FARIA, C. and JACINTO, A. (2006). Distinct mechanisms regulate hemocyte chemotaxis during development and wound healing in Drosophila melanogaster. J Cell Biol173: 405-416.
WOOD, W. and JACINTO, A. (2007). Drosophila melanogaster embryonic haemocytes: masters of multitasking. Nat Rev Mol Cel/ Bio/8: 542-551.

YANO, T. and KURATA, S. (2008). Induction of autophagy via innate bacterial recognition. Autophagy 4: 958-960.

ZAFFRAN, S. and FRASCH, M. (2002). Early signals in cardiac development. Circ Res 91: 457-469.

ZANET, J., STRAMER, B., MILLARD, T., MARTIN, P., PAYRE, F. and PLAZA, S. (2009). Fascin is required for blood cell migration during Drosophila embryogenesis. Development 136: 2557-2565.

\section{Further Related Reading, published previously in the Int. J. Dev. Biol.}

See our recent Special Issue Placenta edited by Joan S. Hunt and Kent L. Thornburg at: http://www.ijdb.ehu.es/web/contents.php?vol=54\&issue=2-3

A novel role of the glial fate determinant glial cells missing in hematopoiesis Cécile Jacques, Laurent Soustelle, István Nagy, Céline Diebold and Angela Giangrande Int. J. Dev. Biol. (2009) 53: 1013-1022

Tracing the hemangioblast during embryogenesis: developmental relationships between endothelial and hematopoietic cells Thierry Jaffredo, Karine Bollerot, Daisuke Sugiyama, Rodolphe Gautier and Cécile Drevon Int. J. Dev. Biol. (2005) 49: 269-277

Of birds and mice: hematopoietic stem cell development Isabelle Godin and Ana Cumano Int. J. Dev. Biol. (2005) 49: 251-257

\section{Embryonic development of the human hematopoietic system}

Manuela Tavian and Bruno Péault

Int. J. Dev. Biol. (2005) 49: 243-250

Multilineage hematopoietic progenitor activity generated autonomously in the mouse yolk sac: analysis using angiogenesisdefective embryos

Christine Rampon and Philippe Huber

Int. J. Dev. Biol. (2003) 47: 273-280
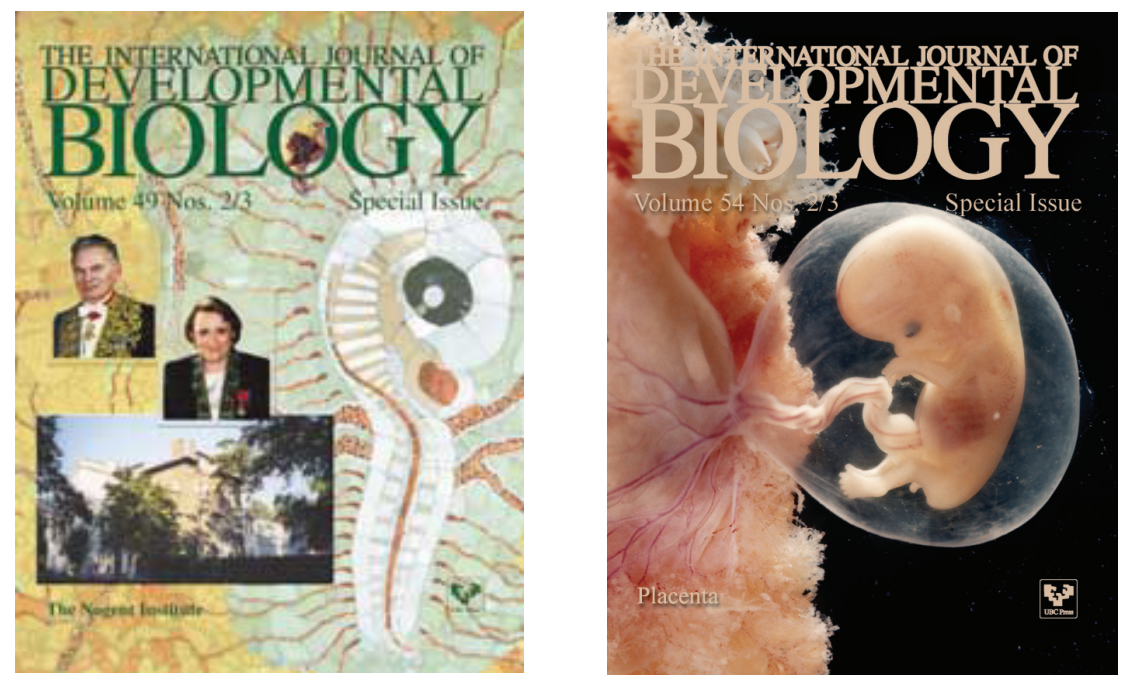

5 yr ISI Impact Factor $(2009)=3.253$
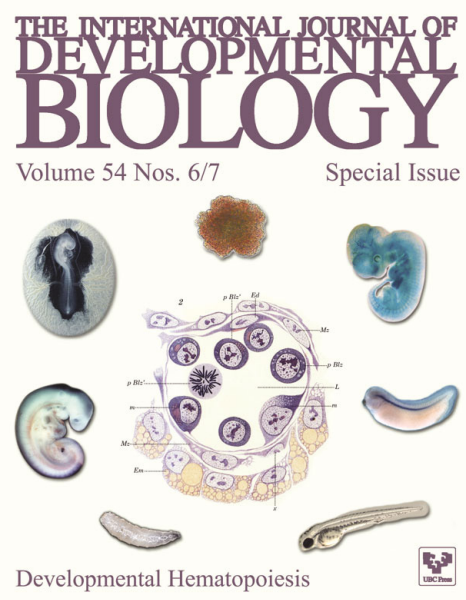